Arrqueologia Pública

ARTIGO

\title{
O LEGADO DO PE. JOÃO ALFREDO ROHR S. J.: \\ REFLEXÕES SOBRE SUA TRAJETÓRIA NA ARQUEOLOGIA BRASILEIRA
}

Fabiana Comerlato

No. 10

ISSN 2237-8294

dezembro de 2014 


\title{
ARTIGO
}

\section{O LEGADO DO PE. JOÃO} ALFREDO ROHR S. J.:

\section{REFLEXÕES SOBRE SUA TRAJETÓRIA NA ARQUEOLO- GIA BRASILEIRA}

\section{Fabiana Comerlato ${ }^{1}$}

\section{RESUMO}

No cômputo de arqueólogos que se destacaram na década de 60 do século XX na pesquisa e na luta pela preservação dos sítios arqueológicos brasileiros, surge à figura de João Alfredo Rohr que exerceu papel fundamental na consolidação da arqueologia catarinense, deixando um importante legado científico para as futuras gerações. O objetivo deste artigo é fazer um retrospecto da trajetória profissional do arqueólogo Rohr e avaliar o seu contributo para a arqueologia brasileira, em especial do Estado de Santa Catarina.

Palavras-chaves: Arqueologia brasileira; Patrimônio Cultural; Museu; João Alfredo Rohr.

\begin{abstract}
On investigating archaeologists who were prominent in research on and the struggle to preserve Brazilian archaeological sites during the 1960s, João Alfredo Rohr emerges. He performed a fundamental role in consolidating archaeology in Santa Catarina, leaving an important scientific legacy for future generations. The aim of this article is to take a retrospective look at the archaeologist, Rohr's professional trajectory and evaluate his contribution to Brazilian archaeology, particularly in the State of Santa Catarina.
\end{abstract}

Keywords: Brazilian archaeology; Cultural Heritage; Museum; João Alfredo Rohr.

1 Doutora em História, área de concentração Arqueologia, professora da UFRB. Contato: fabilato@gmail.com 


\section{RESUMEN}

En el recuento de arqueólogos que se destacaron en la década de 60 del siglo XX en la investigación y en la lucha por la preservación de los sitios arqueológicos brasileños, surge la figura de João Alfredo Rohr quien ejerció un papel fundamental en la consolidación de la arqueología catarinense, dejando un importante legado científico para las futuras generaciones. El objetivo de este artículo es realizar una retrospectiva de la trayectoria profesional del arqueólogo Rohr e evaluar su contribución para la arqueología brasileña, en especial la del Estado de Santa Catarina.

Palabras-clave: Arqueología brasileña; Patrimonio Cultural; Museo; João Alfredo Rohr.

\section{INTRODUÇÃO}

A memória é uma ferramenta que usamos para lembrar o que nos faz sentido. Portanto, nos parece importante o exercício de rememorar pessoas, objetos, coleções e museus, pois a construção do conhecimento arqueológico está alicerçada nestas bases de referência. No Estado de Santa Catarina, atribuímos ao Pe. João Alfredo Rohr (1908-1984) o título de "Pai da Arqueologia Catarinense", justamente pela dimensão de seus feitos e o significado deles até hoje. Em 2014, três datas convergem e podem ser lembradas por nós: os 30 anos de falecimento de Pe. Alfredo Rohr, mesmo ano em que foi tombada sua coleção pela Fundação Catarinense de Cultura, e, principalmente, os 50 anos de criação do Museu do Homem do Sambaqui. As lembranças destes marcos cronológicos nos abrem caminho para a reflexão da importância do legado científico de Rohr e a extensão de sua obra, que continua ainda a provocar interjeições e expressões de admiração nos jovens em visita ao museu.

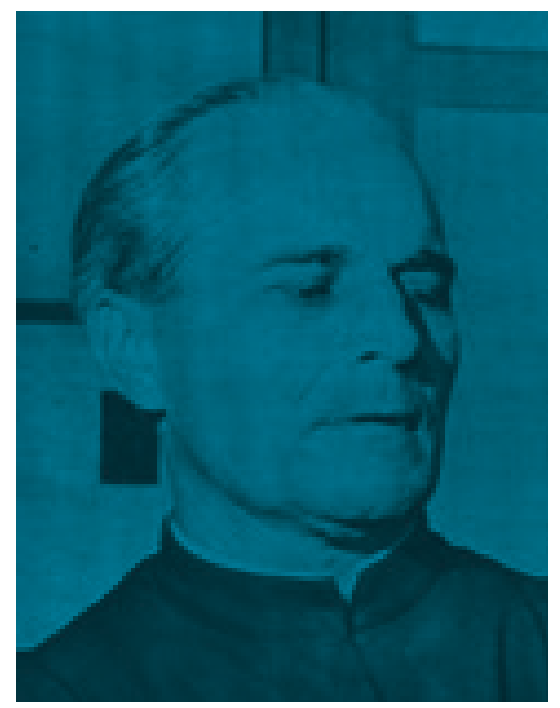

Fig. 1: Pe. João Alfredo Rohr. Extraído de: Revista Manchete, n505, ano 9, Rio de Janeiro, 23 de janeiro de 1961, p. 120. 


\section{ROHR E SUA ATUAÇÃO NA ARQUEOLOGIA}

A comunidade arqueológica contemporânea tende a perceber mais a figura do "Rohr arqueólogo". Porém, seria limitante enquadrá-lo em um único adjetivo. Através de revisão bibliográfica, podemos encontrar diversas biografias sobre o Pe. Rohr, escritas em geral por pessoas que tiveram uma convivência próxima, a exemplo de jesuítas (ETGES, 1984; SCHMITZ, 2009), intelectuais catarinenses (PÍTSICA, 1984), pessoas da comunidade (NUNES, 2000) e arqueólogos (REIS \& FOSSARI, 2009). Podemos dizer que o Pe. Rohr embutiu seu espírito e modo de fazer em muitas comunidades e instituições, seja no fazer espiritual, na ação em prol da cultura, em especial da arqueologia.

Nos anos 50 do século XX, Rohr destacava-se como um excelente gestor educacional na direção do Colégio Catarinense e um hábil articulador na criação de novas instituições de ensino em Santa Catarina - a exemplo da Faculdade Catarinense de Filosofia (CARMINATI, 2009: 7). Rohr nunca abdicou de sua missão educadora, acumulando décadas de experiência no ensino das Ciências da Natureza (Física, Química e Biologia). Podemos dizer que seria injusto lhe atribuir à alcunha de autodidata em arqueologia, pois além de sua formação humanística sempre esteve atualizado no que era de mais moderno na arqueologia, transpondo conhecimentos e criando novas metodologias $^{2}$. Dado este reconhecimento de sua importância, a Sociedade de Arqueologia Brasileira conferiu em suas reuniões bianuais o Prêmio Padre João Alfredo Rohr aos arqueólogos de destaque.

Rohr, após uma aproximação com a arqueologia, faz sua primeira escavação, em 1958, no sítio arqueológico de Caiacanga Mirim junto à Base Aérea de Florianópolis. A partir daí, sucessivas campanhas somaram-se, num total de 18 projetos executados: nos sambaquis da Ilha de Santa Catarina, entre 1959 a 1961; nos sítios arqueológicos do Vale do Rio D’Una em Imbituba, 1961; nos sítios arqueológicos da Praia da Tapera e Ribeirão na Ilha de Santa Catarina, 1962 a 1967; nos sítios arqueológicos do município de Itapiranga, 1966-67/1970-71; nos sítios arqueológicos do Planalto Catarinense (municípios de Petrolândia, Atalanta, Imbúia, Alfredo Wagner, Rancho Queimado e Angelina), 1966-67/1970-71, nas inscrições rupestres em Urubici e municípios vizinhos, 1967; no sítio arqueológico de Alfredo Wagner, SC-VI-13, 1967-1969; nos sítios arqueológicos do município de Jaguaruna, 1968; nos petróglifos da Ilha de Santa Catarina e ilhas adjacentes, 1969-1974; no sítio da Armação do Pântano do Sul - Ilha de

2 A criação do método de cimentação de esqueletos arqueológicos (ROHR, 1970). 


\section{FABIANA COMERLATO}

Santa Catarina, 1971; no sítio arqueológico no Balneário de Cabeçudas, Itajaí, 1975; no sítio arqueológico do Pântano do Sul - Ilha de Santa Catarina, 1977-78; no sítio arqueológico da Praia das Laranjeiras, Balneário Camboriú, 1982; no sambaqui da Balsinha I, Imbituba, 1982; nos sítios arqueológicos no município de Urussanga, 1982. As campanhas de campo totalizaram o registro de 430 sítios arqueológicos no Estado de Santa Catarina (SANTA CATARINA, 1984: 22). Segundo Pe. Pedro Ignacio Schmitz, podemos conferir mais uma indicação superlativa, seguramente, ainda hoje, de que Rohr foi um dos arqueólogos que mais escavou no Brasil (CARBONERA, 2006: 378).

Apesar de ser uma "equipe de um homem só", como denomina Pe. Schmitz, ofereceu para muitos estagiários e estudantes uma escola prática em suas escavações, em uma época extremamente difícil no Brasil de se obter formação em Arqueologia (SCHMITZ, 2009: 18). Nos trabalhos de campo, os participantes eram compostos de estagiários, estudantes, professores, arqueólogos e operários - a maioria destes últimos cedidos pelas prefeituras. A equipe geralmente ficava alojada em casas alugadas próximas ao sítio. Verificamos nos relatórios datilografados por Rohr, o predomínio dos meses das férias de verão e inverno como períodos para as escavações, exceto os trabalhos de salvamento. Em campo, a rotina de trabalho era árdua. As escavações eram feitas em níveis artificiais de dez centímetros, elaboravam-se plantas de topo, perfis estratigráficos verticais e horizontais das trincheiras abertas e eram anotadas todas as informações relevantes no diário de campo. Além de ter realizado o registro fotográfico das etapas da escavação.

Durante toda a sua carreira na Arqueologia, de 1950 a 1982, publicou suas descobertas e resultados em 92 revistas, jornais e outros periódicos, além de divulgar suas pesquisas e ações preservacionistas em entrevistas para rádio e televisão (SANTA CATARINA, 1984). Este caráter polivalente de transpor a ciência arqueológica em diversos meios e linguagens lhe garantiu mais um título: o de arqueólogo mais lido no Brasil (SCHMITZ, 2009: 18). 


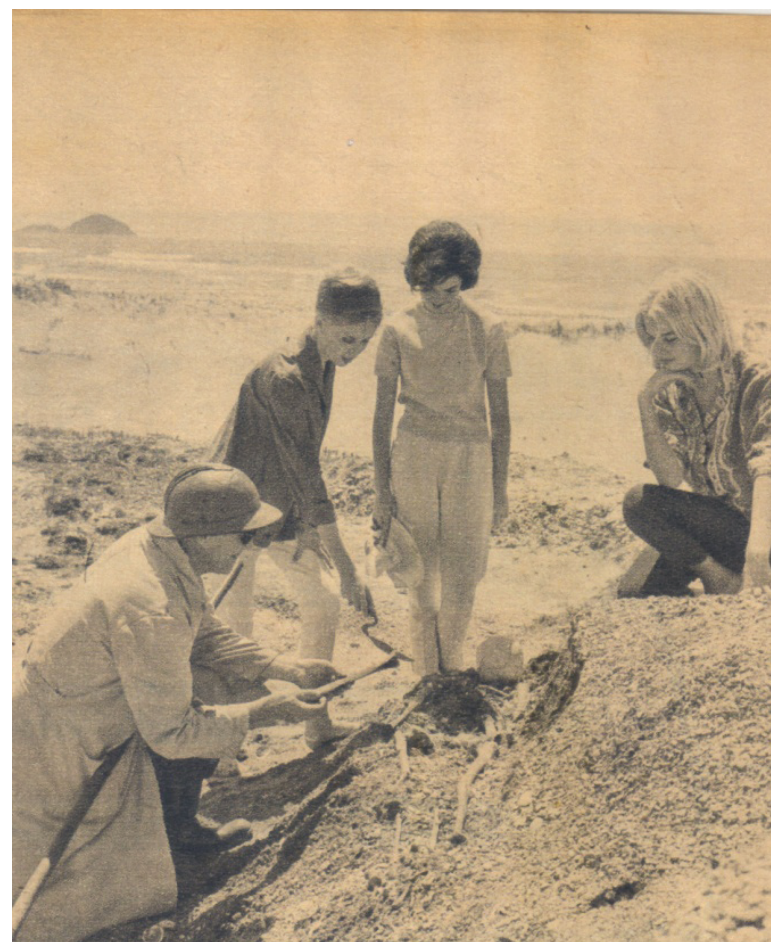

Fig. 2: João Alfredo Rohr em escavações em um sambaqui. Referência: Revista Manchete, nº505, ano 9, Rio de Janeiro, 23 de janeiro de 1961.

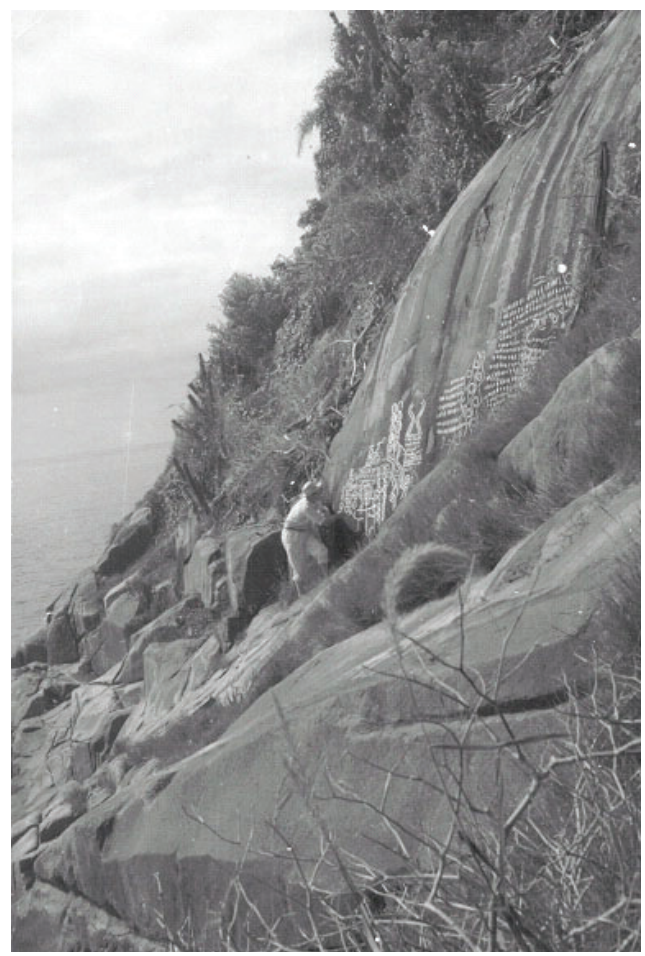

Fig. 3: João Alfredo Rohr durante o processo de documentação das gravuras do Letreiro do Arvoredo. Data: 1968. Acervo: Museu do Homem do Sambaqui Padre João Alfredo Rohr, S.J.

\section{ROHR E A FORMAÇÃO DE ACERVOS E MUSEUS}

Desde sua fundação, o Colégio Catarinense abriga um museu e laboratórios que faziam parte do curso científico: "O Museu de Historia Natural, criado no início do século XX, tinha coleções de mamíferos, aves e ovos, anfíbios, moluscos, botânica e mineralogia, sendo enriquecido por doações de entidades e pessoas mormente alunos egressos do colégio e suas famílias" (DALLABRIDA, 2012: 158). O museu dentro de uma instituição educacional jesuítica cumpria um papel de cartão de visitas da instituição, um espaço de atividades empíricas para seus alunos e de pesquisa para Rohr onde passava grande parte do seu tempo, em conciliação com sua vocação religiosa.

Pe. Rohr começa a se interessar por arqueologia em suas saídas de campo em busca de orquídeas, quando encontra sítios arqueológicos pela Ilha de Santa Catarina. O redirecionamento em suas pesquisas em parte se deve ao Padre Balduíno Rambo e, posteriormente, ao apoio do Pe. Ignacio Schmitz. Em 1948, Rohr compra a Coleção Carlos Berenhäuser³ ${ }^{3}$ dando início ao acervo arqueológico (SANTA CATARINA, 1985:

3 A coleção Berenhäuser apresenta quase que exclusivamente cerâmica guarani, contando com 
20-21).

Em sua construção diária da história das populações indígenas pré-coloniais, Rohr começa a formar e catalogar o acervo que denominará de Museu do Homem do Sambaqui - a primeira instituição especializada em pesquisas arqueológicas no Estado. Com nova configuração, o museu foi fundado em 03 de outubro de 1964, tendo como entidade mantenedora a Sociedade Literária Antônio Vieira. Inicialmente, o museu era denominado "Museu do Homem Americano", sendo mudado para Museu do Homem do Sambaqui em 1965 (SCHMITZ, 2009: 18).

O modo de aquisição deste diversificado acervo deu-se de diversas formas: compra, doação e, principalmente, através das pesquisas arqueológicas efetuadas por Pe. Rohr. No Cadastro dos Museus Catarinenses da Fundação Catarinense de Cultura, segundo informações de 1979, o depósito do museu contava com 130.000 peças antropológicas e 12.000 arqueológicas. O acervo conta com exemplares arqueológicos, eclesiásticos, etnográficos, malacológicos, numismáticos paleontológicos e animais taxidermizados.

O acervo exposto reúne peças de várias escavações, destacando-se as vitrines com os esqueletos, aos com zoólitos e as urnas funerárias. Era objeto de orgulho especial dos sepultamentos da Tapera, uma vértebra transpassada por uma ponta em osso (NUNES apud CRUZ, 2005: 136; SANTA CATARINA, 1984: 28). Os animais taxidermizados se prestam a abordagem biográfica por terem se transformado em cultura material (LOUREIRO, 2012: 100). O peixe lua e a onça pintada chamam a atenção: o primeiro pela sua raridade e a segunda pela história de sua aquisição, que nos presta a uma abordagem biográfica do objeto:

A região de Urubici, em tempos pré-históricos, era habitada por povos trogloditas, que mo-
ravam em galerias subterrâneas, cavadas na rocha mole de arenito. Algumas destas galerias
alcançam cem metros de comprimento, tendo, em média, metro e meio de diâmetro. Pene-
tramos em muitas daquelas galerias, completamente desarmados, munidos, apenas, de um
lampião de pressão Colemann, para iluminar o interior das mesmas. Não raro, encontramos
no interior das mesmas, sinais evidentes do trabalho de tatús, tamanduás, gatos do mato e
graxains. Sabíamos, que, na região, ainda, havia onças pardas, chamadas também, pumas,
sussuaranas ou "leão brasileiro". Não imaginávamos, porém, que poderiam aparecer, ainda
onças pintadas ou jaguares. Ficamos, por isto, surpreendidos, quando retornamos ao pla-
nalto, em princípios de fevereiro, para prosseguir as pesquisas nas galerias subterrâneas e
apresentaram-nos a pele de enorme, onça pintada, morta dois dias antes. Era animal extre-
mamente gordo. Andava cevando-se de ovelhas, novilhos, pôtros e, por certo, também, de
veados e outra caça, ainda frequente na região.
Na madrugada de $29 / 01 / 72$, matara e devorara um burro, triturando até os ossos do mesmo.
Perseguida pelo capataz da Fazenda da Pedra Branca e mais um peão, enfrentou os cachor-

dezenas de objetos inteiros e aproximadamente 80.000 fragmentos. O material lítico consta aproximadamente de 8.000 peças de origem sambaquiana. A coleção formou-se com artefatos coletados por amadores, principalmente por Carlos Berenhäuser e pela população (SCHMITZ, 1959: 268-269). 


\begin{abstract}
ros, juntos, a uma árvore caída. Os dois caçadores imaginavam estarem no encalço de um puma ou "leãozinho", bastante inofensivo. Qual não foi o seu espanto, quando toparam enorme onça pintada, pronta para o bote? O capataz, Ermelindo Pedro Ribeiro, quando se deu conta, já se encontrava, quase, nas faces da fera e não teve tempo para recuar. Por isto, descarregou a sua armazinha, calibre 32, a queima-roupa no "bicharedo". Teve sorte, atingindo-o direto no coração. Assim mesmo, mortalmente ferida, a onça saltou sobre ele, cravando-lhe os dentes e as garras, causando-lhe ferimentos profundos, no rosto no peito e nos braços. Socorrido pelo companheiro, este descarregou segundo tiro na vista da onça, que acabou, imobilizando-a.

Imagine só, se dentro de uma galeria subterrânea, armados tão somente, com um foco de luz, topassemos um "bichão" destes! Já pensou! por certo esta onça não é a única na região de Urubici, onde existem campos imensos, perdidos em mata baixa, cavernas e grotões sem conta. Compramos a pele e o esqueleto da onça, que será montada para o Museu do Homem do Sambaqui, como atração turística e instrução da mocidade estudiosa, que poderá admirá -la, sem correr risco de vida. (ROHR, s/d.)
\end{abstract}

A partir de meados do século XX, o cenário cultural catarinense teve uma expansão no campo museológico. O historiador e arqueólogo Walter Piazza traz uma listagem de coleções arqueológicas e seus locais de guarda no Estado de Santa Catarina em 1965: o Museu Nacional de Imigração e Colonização, Museu Anita Garibaldi, Museu do Homem do Sambaqui, Museu Arquidiocesano "Dom Joaquim”, Museu do Colégio Dehon, Museu do Ginásio "São João Batista", Coleção Teodoro Saade, Coleção Kurt Braunsburger, Coleção Jacob Andersen (PIAZZA, 1966: 460-461).

Durante a década de 60 , surgem várias instituições voltadas à preservação dos acervos arqueológicos, além do Museu do Homem do Sambaqui, foram fundados o Museu Arqueológico de Sambaqui de Joinville e o Museu Universitário da Universidade Federal de Santa Catarina (SOUZA, 2007: 16). A atuação de Rohr no campo dos museus de arqueologia também acontecia através do fortalecimento das relações institucionais.

No âmbito da Universidade Federal de Santa Catarina, com o desenvolvimento das pesquisas arqueológicas, foi criado o Instituto de Antropologia, em 30 de dezembro de 1965, sob a direção de Oswaldo Rodrigues Cabral. A instalação oficial do Instituto ocorre em 29 de maio de 1968. Com a reforma universitária de 1970, o mesmo passou a denominar-se Museu de Antropologia e em 1978 passou a ser chamado Museu Universitário.

Logo quando o Museu do Homem do Sambaqui de Joinville (MASJ) foi criado em 1969, Rohr acompanha o convenio entre MASJ e IPHAN. Em 1972, quando o museu é oficialmente inaugurado dentre as solenidades presentes, estava o Pe. João Alfredo Rohr como presidente do Conselho Estadual de Cultura (TAMANINI, 1994: 91).

Ainda neste cenário museológico, Rohr pôde atuar na preservação no oeste de Santa Catarina, em visitas a diversas localidades do Estado, como ocorreu em Itapiranga, em 1966, com o mapeamento de 53 sítios arqueológicos às margens do rio Uruguai, 
sendo a maioria sítios cerâmicos Guarani (CARBONERA, 2011: 29). Na época, Rohr estimulou a preservação e a guarda dos acervos nas regiões de origem, como depois irá preconizar a Carta de Lausanne:

\begin{abstract}
Os sitiantes recolhiam as peças mais expressivas e davam-nas de presente à primeira pessoa que nelas mostrasse algum interesse. Muitas vêzes, quebravam as igaçabas e partiam os artefatos, para ver se continha ouro. Em vista disto e da grande abundância e variedade de material arqueológico que, aparecendo por tôda a parte, estava sendo destruido, delapidado e disperso, sem utilidade alguma, fizemos uma intensa campanha de esclarecimento, atravez de conferências e palestras radiofônicas e convencemos o povo e a Prefeitura Municipal da necessidade urgente de fundarem um Museu Arqueológico, ao qual fôsse recolhido todo o material encontrado nas roças, nos matos e nos pastos, para assim defenderem e conservarem o patrimônio cultural do município. Atravez do rádio instruímos o povo, sôbre a maneira mais segura de escavar uma igaçaba, atingida por um arado numa roça, sem partí-la (ROHR, 27/04/1966 a 01/06/1966).
\end{abstract}

Em uma época que a arqueologia ainda se recolhia aos museus e centros de pesquisa e caminhava muito timidamente nas ações de educação patrimonial, percebemos neste trecho de seu relatório de viagem, sua consciência do papel dinamizador que as comunidades poderiam agir em prol de seu patrimônio arqueológico. O Museu Comunitário de Itapiranga tornou-se realidade em nove de agosto de 1978, quando é registrado em cartório pelos membros do Conselho Comunitário de Itapiranga, com a presença de Rohr como representante do IPHAN ${ }^{4}$. Segundo Denise Argenta, este museu é o segundo mais antigo na região oeste de Santa Catarina. Em 1990, a instituição recebe edificação própria e em 2007 tem seu nome alterado para Museu Comunitário Almiro Theobaldo Muller (ARGENTA, 2011: 9). Atualmente, este museu é mantido pela municipalidade com um acervo bastante variado, agrega várias coleções dentre elas, ganha destaque de arqueologia (PIOVESAN, 2008: 58).

Já no litoral, em 1977, as escavações do sítio Laranjeiras procedidas por Rohr compuseram o acervo do museu de Balneário Camboriú, localizado no Centro de Promoções e Informações Turísticas S/A - CITUR. Atualmente, dada às alterações de nomenclatura que se sucedeu durante sua existência, o museu arqueológico faz parte do Complexo Ambiental Cyro Gevaerd, pertencente ao Instituto Catarinense de Conservação da Fauna e Flora.

Rohr continua a ocupar grande parte de seu tempo com o Museu do Homem do Sambaqui. Logo após o seu falecimento, houve um temor que o acervo de toda sua trajetória fosse deslocado para outro local. Sendo assim, a coleção foi tombada pelo Estado e União. O tombamento da Coleção Arqueológica Padre João Alfredo Rohr ${ }^{5}$

$4 \mathrm{http}: / /$ www.itapiranga.sc.gov.br/conteudo/?item=23628\&fa=5001

5 A Coleção Arqueológica João Alfredo Rohr está assim distribuída: as peças depositadas nas 
data de 1984 pelo Estado e pelo IPHAN foi efetivado em 1986 (SOUZA, 1992: 25). A coleção passa a ter como responsável outro arqueólogo da mesma congregação: o Pe. Pedro Ignácio Schmitz. Decorridos anos fechado ao público e alvo de diversas manifestações da imprensa local, finalmente, o museu foi reinaugurado em 29 de agosto de 1998, passando a incorporar o nome seu mentor: Museu do Homem do Sambaqui Padre João Alfredo Rohr, S.J. (foto 4).

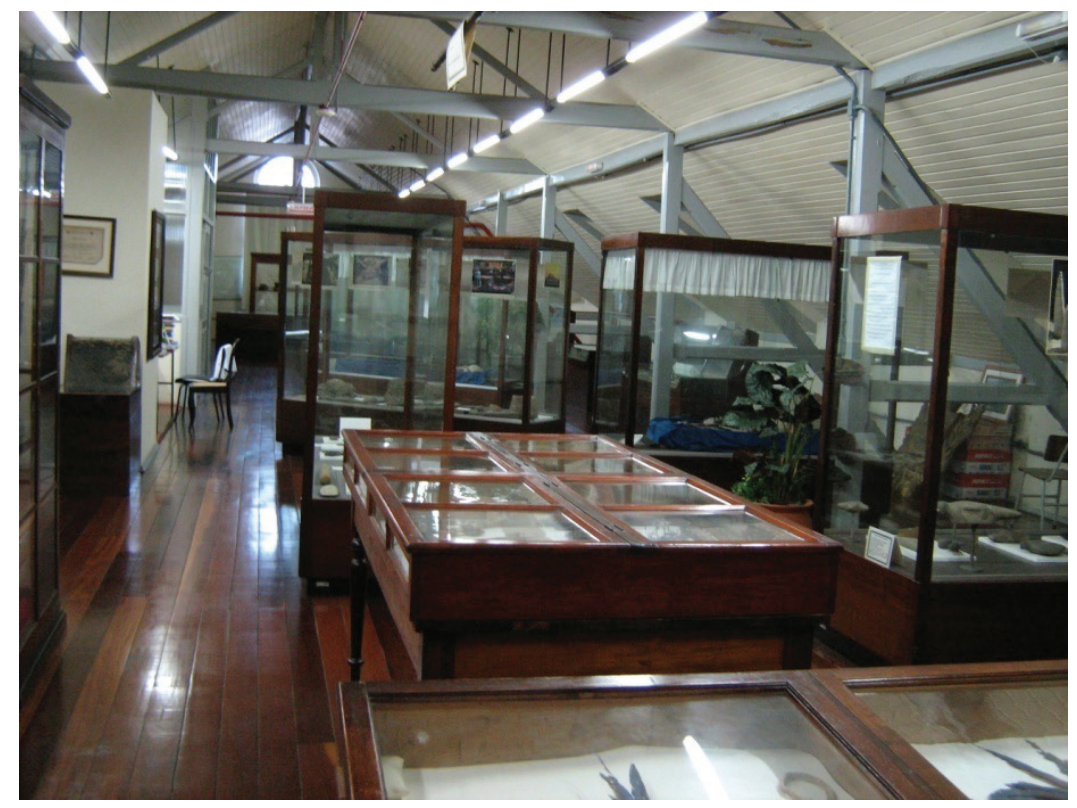

Fig. 4: Interior do Museu do Homem do Sambaqui “Pe. João Alfredo Rohr, S.J.”. Foto: Fabiana Comerlato, 2008.

\section{ROHR COMO DEFENSOR DO PATRIMÔNIO}

Concomitante às suas pesquisas, Rohr participou de um grupo de intelectuais militantes que, articulados em cada Estado, puderam atuar em prol ao patrimônio e preservação dos sambaquis, junto com José Ascenção Loureiro Fernandes ${ }^{6}$, Paulo Duarte ${ }^{7}$ e

dependências particulares do Colégio Catarinense, em Florianópolis, Santa Catarina; as peças em exposição no Museu do Homem do Sambaqui (Colégio Catarinense), em Florianópolis, Santa Catarina; as peças em exposição no Museu Arqueológico e Oceanográfico do Balneário de Camboriú, Santa Catarina; e as peças em exposição na Academia Nacional da Policia Federal em Brasília (Processo 1.129-T-84) (IPHAN, 2013).

6 José Loureiro (1908-2003) foi médico, indigenista, diretor do Museu Paranaense, fundador e diretor do Departamento de Antropologia da UFPR, fundador do Museu de Arqueologia e Artes populares em Paranaguá. Enfim, um precursor na arqueologia, etnologia indígena e cultura popular do Estado do Paraná (CHMYZ, 2005).

7 Paulo Duarte (1899-1984) foi um humanista, professor e arqueólogo, criou a Comissão de 
Luiz Castro Faria ${ }^{8}$ (CRUZ, 2012: 139). A ação articulada e contínua desta geração de intelectuais propiciou o fortalecimento da arqueologia através da criação de cursos de formação específicos, unidades museológicas e na concepção de uma legislação que garantisse a salvaguarda dos sítios arqueológicos pré-históricos (BARRETO, 1999-2000: 40).

A comissão do projeto de Lei nº3537 de 29 de novembro de 1957 incluía os nomes de Rodrigo de Melo Franco Andrade, Diretor do Patrimônio Histórico e Artístico Nacional; José Candido Melo Carvalho, diretor do Museu Nacional; Loureiro Fernandes, da Faculdade de Filosofia da UFPR e Paulo Duarte da Comissão de Pré-história da USP (ESTADOS UNIDOS DO BRASIL, 1959). Este projeto de lei com pequenas alterações, posteriormente, se transformou na Lei n ${ }^{\circ} 3924 / 61$, que confere ao Estado Nacional a proteção dos sítios arqueológicos em território brasileiro.

Nos anos 70, Pe. Rohr tornou-se representante do IPHAN para a área de arqueologia no Estado de Santa Catarina, vistoriou os sítios do litoral e interior, conscientizando autoridades e denunciando à justiça federal as depredações e vandalismos verificados. Prestou depoimento em inquérito policial contra a Prefeitura de Laguna, contra os depredadores em Jaguaruna e de outras localidades.

Segundo relatório de Rohr ao MEC/SPHAN, durante os anos de 1972 a 1977 sofreu muitas ameaças, por parte de exploradores clandestinos de sambaquis quando realizara inspeções rotineiras. As ações do Pe. João Alfredo Rohr em sua função como representante do SPHAN teve amplo reconhecimento da comunidade científica da época. O combate contínuo contra interesses econômicos e políticos em prol da preservação dos sambaquis foi reconhecido e apoiado em moção assinada por 237 antropólogos na 9a Reunião da Sociedade Brasileira de Antropologia em 1974 (SANTA CATARINA, 1985: 38).

Pe. Rohr constatou que algumas prefeituras municipais do Estado nos anos 60 e 70 praticaram ações contra diversos sítios arqueológicos. Em 29 de janeiro de 1974, foram interrompidas as escavações na Armação do Pântano do Sul:

Constatamos que a Prefeitura Municipal de Laguna, havia compactado quatro quilômetros da estrada do Farol de Santa Maria com conchas de sambaquis. Em Jaguaruna surpreendemos dois indivíduos, ocupados em peneirar conchas do sambaqui da Garoupaba. Nos sambaquis da Carniça II, em Laguna; do Siqueiro e da Samambaia, em Imaruí, as obras

Pré-História da USP em 1952 (FUNARI, 1994).

8 Luiz Castro Faria (1913-2004) foi professor de Antropologia da UFRJ e diretor do Museu Nacional. A mais relevante pesquisa arqueológica que realizou foi no sambaqui da Cabeçuda em Laguna (CRUZ, 2012). Em 1963, Castro Faria colaborou durante uma semana com Rohr nas escavações da Tapera, lhe aconselhando a solicitar bolsa do Conselho Nacional de Pesquisas (PISANI, c. 1982). 
de demolição estavam prosseguindo.(...) Em fins de março recebemos novas denúncias de destruição de sambaquis, vindas do Município de Garuva, divisa com o Paraná.(...) Extensos trechos de estradas municipais, haviam sido, recentemente, compactadas com material retirado dos sambaquis (ROHR, $1^{\circ}$ de janeiro a 30 de junho de 1974).

Nesta época, as comunidades que viviam da exploração dos sambaquis em Laguna o respeitavam mais pelo fato de ser padre do que fiscal do SPHAN (FILETI, 2004: 26). Os moradores da comunidade de Campos Verdes, onde fica o complexo de sambaquis da Carniça, viam Rohr como o homem que "fechou" o Carniça, sendo assim, o responsável por tirar o sustento dos moradores (FILETI, 2004: 52). Lembremos que era consenso entre as comunidades a explicação da origem do sambaqui como testemunho do dilúvio; o conhecimento científico dos sambaquis ainda começava a ser difundido de forma mais ampla.

Além de sambaquis mutilados e em constante ameaça, em março de 1979, Rohr verificou a destruição de uma laje com mais de 100 amoladores na Barra da Lagoa, em Florianópolis. A destruição foi causada pela construção de uma ponte pênsil que dá acesso à Prainha da Barra, uma obra da Prefeitura Municipal. Esta oficina lítica, denominada atualmente de Oficina Lítica Rio da Lagoa I, ficou embaixo de um dos pilares da referida ponte (foto 5; AMARAL, 1995).

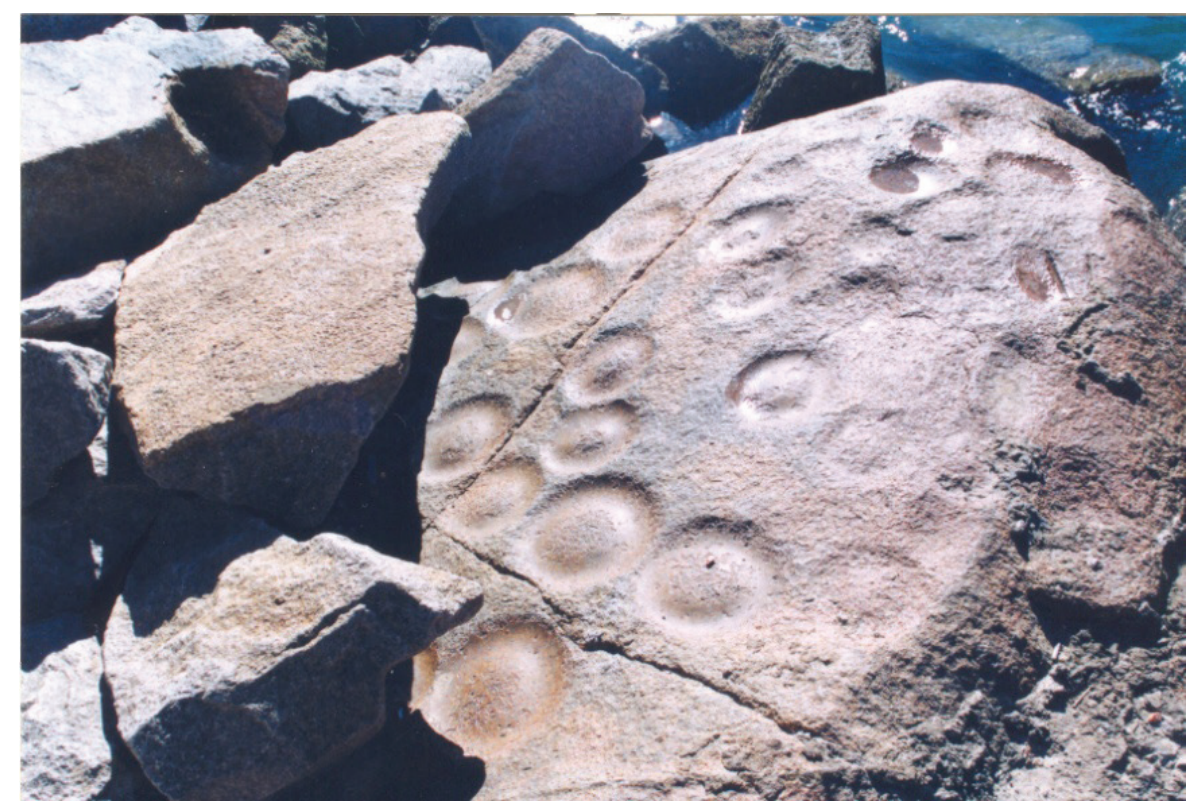

Fig. 5: Foto da Oficina Lítica Rio da Lagoa I. Foto: Fabiana Comerlato.

Segundo Rohr, os principais inimigos na preservação dos sítios são:

(...)a lavoura mecanizada, a abertura de novas estradas, os loteamentos, particularmente no litoral, e as represas hidro-elétricas, que vão submergindo sítios arqueológicos às centenas. 
Outra ameaça constante são os turistas, dificeis de fiscalizar o que, permanentemente, continuam fazendo pequenas depredações nos sítios arqueológicos (ROHR, s/d.).

O eminente antropólogo Sílvio Coelho dos Santos ${ }^{9}$, de maneira muito crítica, nos brinda com suas indagações perturbadoras, ainda nos parece muito contemporâneas, no sentido da ausência na aplicação de ferramentas de gestão do patrimônio arqueológico pelas esferas governamentais:

A campanha encetada pelo Pe. Rohr não somente deve merecer todo apoio dos homens lúcidos e responsáveis desta terra. É necessário, e urgente, que medidas efetivas sejam tomadas. Em São Paulo, no Paraná e no Rio Grande do Sul os governos lograram coibir a destruição dos sítios pré-históricos. Por que não será possível aniquilar com as aspirações destrutivas de uns poucos interessados em lucros fáceis, aqui em Santa Catarina? Por que não será possível às Prefeituras Municipais onde se concentram importantes monumentos pré-históricos criar parques locais, visando o resguardo dos sítios e à criação de ambientes públicos de futura importância paisagística e turística? Por que o Governo Estadual não pode organizar um setor destinado ao tombamento e preservação desse patrimônio? (SANTOS, 1972: 119)

\section{CONSIDERAÇÕES FINAIS}

Nesta tentativa de avaliar o legado científico de Pe. Rohr, podemos perceber a magnitude de seu trabalho em prol da cultura catarinense. No que tange à arqueologia, sua obra pode ser considerada como fonte básica no entendimento da pré-história na região sul do Brasil. O seu caráter pioneiro propiciou novos delineamentos para a arqueologia do século XXI, Pe. Rohr foi um “(...) desbravador de um território inculto, preparando -o para uma nova etapa e buscando garantir os sítios e o material para as gerações que o sucederiam" (SCHMITZ, 2009: 20).

9 "Natural de Florianópolis, Sílvio Coelho dos Santos nasceu em 1938. Cursou a graduação em História na UFSC (1960), Especialização em Antropologia Cultural e Sociologia na UFRJ (1963) e Doutorado em Antropologia na USP (1972). Professor da UFSC desde 1962, foi chefe do Departamento de Ciências Sociais, coordenador da Pós-graduação em Ciências Sociais, PróReitor de Pesquisa e Pós-Graduação, Pró-Reitor de Ensino. Sua participação foi fundamental para a consolidação de Programa de Pós-Graduação em Antropologia Social e para a criação do Departamento de Antropologia da UFSC.Teve participação ativa em instituições científicas e literárias, foi sócio emérito do IHG-SC e secretário regional da Sociedade Brasileira para o Progresso da Ciência (SBPC), destacando-se como Presidente da Associação Brasileira de Antropologia (1992-1994), membro da Academia Catarinense de Letras e pesquisador emérito do CNPq. Faleceu aos 70 anos em 2008" Disponível em http://nepi.ufsc.historico/fundador/ Acessado: 21 set. 2014. 


\section{REFERÊNCIAS BIBLIOGRÁFICAS}

Documentos do Arquivo do SPHAN/ Pró-Memória - $11^{a} \mathbf{S R} / \mathbf{I P H A N} / \mathbf{S C}$

BASTOS, Rossano. Relação das informações contidas sobre material arqueológico em relatórios do Pe. João Alfredo Rohr. $11^{\text {a }}$ CR - SPHAN Pró-Memória - Serviço Público Federal. 29/01/1996.

Orçamento e Quadro de Informações Básicas sobre o cadastramento e Proteção aos Sítios Arqueológicos de Santa Catarina, do Pe. João Alfredo Rohr ao MEC-SPHAN. (sem data- datilografado)

ROHR, João Alfredo. Relatório da Viagem de Prospeção de Sítios Arqueológicos no Municipio de Itapiranga, Oeste Catarinense (Fronteira com a Argentina). De 27/04/1966 a 01/06/1966.

ROHR, João Alfredo. Prospecção de Sítios Arqueológicos nos Municípios de Petrolândia, Atalanta, Imbúia, Alfredo Wagner, Rancho Queimado e Angelina. 23 de novembro de 1966.

ROHR, João Alfredo. O Sítio Arqueológico da Praia das Laranjeiras - Balneário de Camboriú - SC II. (sem data - datilografado).

ROHR, João Alfredo. Caçada de Onça 1972. Novo Inquilino nas Casas Subterrâneas Pré-Históricas de Urubici. (sem data- datilografado).

Relatório do arqueólogo Pe. João Alfredo Rohr do dia $1^{\circ}$ de janeiro a 30 de junho de 1974.

Entrevista feita pelo prof. Osmar Pisani ao arqueólogo João Alfredo Rohr. c. 1982.

AMARAL, Maria Madalena Velho do. As Oficinas Liticas da Ilha de Santa Catarina. 1995. Dissertação. Programa de Pós-Graduação em História, área de concentração Arqueologia, Pontifícia Universidade Católica do Rio Grande do Sul, Porto Alegre, 1995.

ARGENTA, Denise. O ideal de museu e o museu real: uma análise dos museus do Oeste Catarinense. 2011. Dissertação. Programa de Pós-Graduação Mestrado Profissionalizante em Patrimônio Cultural, Universidade Federal de Santa Maria, Santa Maria, 2011.

BARRETO, Cristina. "A construção de um passado pré-colonial: uma breve história da arqueologia no Brasil”. Revista USP, São Paulo, n.44, p. 32-51, dezembro/fevereiro 
1999-2000.

BECK, Anamaria. "Pesquisas de Antropologia em andamento em Santa Catarina (Período: 1965/72)". Anais do Museu de Antropologia da UFSC, ano V. Florianópolis, 1972. 131-153 pp.

CARBONERA, Miriam. "As pesquisas arqueológicas entre o final do século XIX e o início do século XXI”. In: CARBONERA, Miriam; SCHMITZ, Pedro Ignacio (Orgs.). Antes do oeste catarinense: arqueologia dos povos indígenas. Chapecó: Argos, 2011. $17-45 \mathrm{pp}$.

CARBONERA, Miriam. "Assim se fazia arqueologia: entrevista com o arqueólogo Pedro Ignacio Schmitz". Cadernos do CEOM-Chapecó: Argos, vol. 19, n²4, p. 369393, 2006.

CARMINATI, Celso João. "Intelectuais e políticos na expansão do ensino superior catarinense na década de 1950". ANPUH - XXV Simpósio Nacional de História, Fortaleza, 2009.

CHMYZ, Igor. Anais do Seminário Comemorativo do centenário de nascimento do prof. Dr. José Loureiro Ascenção Fernandes (1903-2003). v. 3. Curitiba: CEPA, 2005

CRUZ, Alfredo Bronzato da Costa. "O cotidiano e a prática arqueológica do Pe. João Alfredo Rohr em um conjunto de cartas com o antropólogo Luiz de Castro Faria". Revista Mosaico, v. 5, n. 2, p. 137-157, jul./dez. 2012.

CRUZ, Alfredo Bronzato da Costa. Concha sobre concha: o estudo e a conservação dos sambaquis na correspondência entre Luiz de Castro Faria e Pe. João Alfredo Rohr (1960-1971). 2013. Dissertação. Programa de Pós-Graduação em História, Universidade Federal do Estado do Rio de Janeiro, Rio de Janeiro, 2013.

DALLABRIDA, Norberto. "Os incluídos do exterior: trajetórias sociais de ex-alunos bolsistas de um colégio de elite (1952-1961)". In: LOPES, Sonia de Castro; CHAVES, Miriam Waidenfeld (orgs.). A história da educação em debate: estudos comparados, profissão docente, infância, família e Igreja. Rio de Janeiro: Mauad X, 2012. 155-169 pp.

ESTADOS UNIDOS DO BRASIL. Projeto n.3.537-A, de 1957. Diário do Congresso Nacional, Brasília, DF, ano XIV, nº189, 28 nov. 1959. Seção I, p. 8994-8998.

FILETI, Milton Knabben. A destruição do sambaqui da Carniça visto através de relatos e imagens: um estudo de caso. 2004. Trabalho de Conclusão de Curso. Departamento de História, Centro de Filosofia e Ciências Humanas, Universidade Federal de Santa Catarina, 2004. 
FUNARI, Pedro Paulo. "Paulo Duarte e o Instituto de Pré-História: documentos inéditos". Idéias, Campinas, 1(1): 155-179, jan./jun. 1994.

IPHAN. Lista de Bens Culturais Inscritos nos Livros de Tombo (1938-2012). Rio de Janeiro: IPHAN, 2013. Disponível em <http://www.iphan.gov.br/baixaFcdAnexo. do? $\mathrm{id}=3263>$. Acessado em 25 nov. 2013.

LOUREIRO, Maria Lucia de Niemeyer Matheus. Notas sobre a construção do objeto musealizado como documento". Anais do Museu Histórico Nacional, Rio de Janeiro, v. 44, p. 91-106, 2012.

MARTINS, Maria Cristina Bohn; ROGGE, Jairo. "Por cerrados, matos e pantanais. As experiências de um pioneiro da arqueologia brasileira". Entrevista com Pedro Ignácio Schmitz. História Unisinos 16(2):256-268, Maio/Agosto 2012.

NUNES, Sebastião Manoel. João Alfredo Rohr - SJ: O padre motoqueiro. Florianópolis: Papa-Livro, 2000.

O Homem nasceu no Brasil? Revista Manchete, №505, Rio de Janeiro, p. 120-121, 23 de dezembro de 1961.

PIAZZA, Walter Fernando. "As fontes primárias da história: fontes arqueológicas catarinenses”. Anais do III Simpósio dos Professores Universitários de História-ANPUH, Franca, p. 439-482, 1966.

PIOVESAN, Greyce Kely. Guia de Museus de Santa Catarina. Florianópolis: Fundação Catarinense de Cultura, 2008.

PÍTSICA, Paschoal Apostolo. P. João Alfredo Rohr S.J. Revista do Instituto Histórico e Geográfico de Santa Catarina, nº5, 1984, p. 297-299.

REIS, Maria José; FOSSARI, Teresa Domitila. "Arqueologia e preservação do patrimônio cultural: a contribuição do Pe. João Alfredo Rohr". Cadernos do CEOM - Ano 22, n. 30 - Políticas públicas: memórias e experiências, 2009, p. 265-293.

ROHR, João Alfredo. Normas para a cimentação de enterramentos arqueológicos e montagem de blocos-testemunha. Curitiba: Centro de Ensino e Pesquisas Arqueológicas, 1970. Manuais de Arqueologia, n³.

SANTA CATARINA. Secretaria de Cultura, Esporte e Turismo. Conselho Estadual de Cultura. Aspectos da Vida e da Obra de João Alfredo Rohr, S. J. Florianópolis: Conselho Estadual de Cultura; Instituto Histórico e Geográfico; Colégio Catarinense, 1984.

SANTOS, Sílvio Coelho dos Santos. "Sobre o patrimônio pré-histórico em Santa Catarina". Anais do Museu de Antropologia da UFSC, ano V, nº5, 1972, p. 117-119. 
SCHMITZ, Pedro Ignácio. "A Cerâmica Guarani da Ilha de Santa Catarina”. Pesquisas, $\quad \mathrm{n}^{\circ}$ 3. São Leopoldo: Instituto Anchietano de Pesquisas, 1959.

SCHMITZ, Pedro Ignácio. "João Alfredo Rohr: Um jesuíta em tempos de transição". Pesquisas, Antropologia N ${ }^{\circ}$ 67: 09-22 São Leopoldo: Instituto Anchietano de Pesquisas, 2009.

SOUZA, Alcídio Mafra de. Guia dos Bens Tombados, Santa Catarina. Rio de Janeiro: Expressão e Cultura, 1992.

SOUZA, Flávia Cristina Antunes de. A preservação do patrimônio arqueológico em Joinville/SC: desamontoando conchas e evidenciando memórias. 2007. Dissertação. Programa de Pós-Graduação em História, Universidade Federal do Paraná. Curitiba, 2007.

TAMANINI, Elizabete. Museu Arqueológico de Sambaqui: um olhar necessário. 1994. Dissertação. Programa de Pós-Graduação em Educação, Universidade Estadual de Campinas. Campinas, 1994. 